\title{
Controlling Variable Emittance (MEMS) Coatings for Space Applications
}

\author{
D. Farrarr ${ }^{1}$, W. Schneider ${ }^{1}$, R. Osiander ${ }^{1}$, J.L. Champion ${ }^{1}$, A.G. Darrin ${ }^{1}$ \\ D.Douglas ${ }^{2}$, T.D.Swanson ${ }^{2}$ \\ ${ }^{1}$ Johns Hopkins University Applied Physics Laboratory, Laurel, MD 20723 \\ ${ }^{2}$ NASA Goddard Space Flight Center, Greenbelt, MD 20771 \\ (240)228-7384,Dawnielle.Farrar@jhuapl.edu
}

\begin{abstract}
Small spacecraft, including micro and nanosats, as they are envisioned for future missions, will require an alternative means to achieve thermal control due to their small power and mass budgets. One of the proposed alternatives is Variable Emittance (Vari-E) Coatings for spacecraft radiators. Space Technology-5 (ST-5) is a technology demonstration mission through NASA Goddard Space Flight Center (GSFC) that will utilize Vari-E Coatings. This mission involves a constellation of three (3) satellites in a highly elliptical orbit with a perigee altitude of $\sim 200 \mathrm{~km}$ and an apogee of $\sim 38,000 \mathrm{~km}$. Such an environment will expose the spacecraft to a wide swing in the thermal and radiation environment of the earth's atmosphere. There are three (3) different technologies associated with this mission. The three technologies are electrophoretic, electrochromic, and Micro ElectroMechanical Systems (MEMS). The ultimate goal is to make use of Vari-E coatings, in order to achieve various levels of thermal control. The focus of this paper is to highlight the Vari-E Coating MEMS instrument, with an emphasis on the Electronic Control Unit responsible for operating the MEMS device. The Test \& Evaluation approach, along with the results, is specific for application on ST-5, yet the information provides a guideline for future experiments and/or thermal applications on the exterior structure of a spacecraft.
\end{abstract}

\section{INTRODUCTION}

The Space Technology 5 (ST-5) mission is the fourth space mission in NASA's New Millennium Program (NMP). This program endeavors to validate new technologies that will enable the reduction of weight, size, and costs of future Earth Science missions. Current satellites weigh hundreds to thousands of kilograms $(\mathrm{kg})$ and use hundreds of watts of heater power. Future missions could involve the use of miniature satellites weighing 5 to $10 \mathrm{~kg}$ each that use a fraction of the power associated with larger spacecraft. In order for such size, power, and weight designs to be employed on miniature spacecraft, smaller radiators will be required. Variable Emittance (Vari-E) coatings have proved applicable to a wide range of space applications, particularly in the area of radiators. ${ }^{[1]}$ Studies reveal that Vari-E coatings offer substantial savings in mass and/or power over traditional approaches (i.e. large heaters, variable conductance heat pipes, and mechanical louvers) ${ }^{[2]}$. This paper discusses the use of a Vari-E infrared radiator coating with MEMS shutters that can be opened or closed to vary the emissivity of the radiator surface, thereby providing a thermal path from the external environment to the spacecraft. Utilization of these characteristics on small spacecraft allow us to maintain the same benefits associated with traditional techniques, but on a much smaller scale. Success in this area could lead to great advancements in emerging technologies that require small, low power, and more cost efficient instruments. This experiment will be subject to a radiation environment of $40 \mathrm{krad}$ and is scheduled for launch in November 2004.

\section{INSTRUMENT DESCRIPTION}

The Johns Hopkins University Applied Physics Laboratory (APL) MEMS Variable Emittance Coating (VEC) Instrument consists of two components, namely the MEMS Shutter Array (MSA) radiator and the Electronic Control Unit (ECU). The MSA radiator is physically located on either the top or the bottom deck of the spin-stabilized ST-5 spacecraft whereas the ECU will be located within the spacecraft. The MSA radiator can be operated in both manual and autonomous mode, to evaluate both high and low emittance states.

The MSA radiator is a variable emittance device, consisting of two sections, each containing 18 MEMS Shutter Die (MSD). The sections are divided into 3 subsections each (6 MSDs/subsection), which are independently controlled 
by the ECU. The shutters are in a closed position when no power is supplied, and open upon the application of a 30volt DC signal. The shutters can be independently controlled by the ECU. In manual mode, all shutters can be commanded to be either all open or all close. In automatic mode, the ECU has the ability to independently control the shutter position of the different sections of the MSA and determine the resulting change in radiator substrate temperature. The temperature results are significant because they provide a quantitative record of how well the instrument performs as a thermal device (i.e. functional radiator). The ECU transmits the readings of four temperature sensors, the shutter arrangement, and the shutter status to C\&DH in both automatic and manual mode.

The ECU, from an electronics perspective, makes use of many different components such as a Hi-Voltage Supply, Hi-Voltage Switches, Microcomputer, Program Memory, A/D converter, etc. To aid in the understanding of the controller's function, a flow diagram revealing some of the aforementioned components is provided in Figure 1.

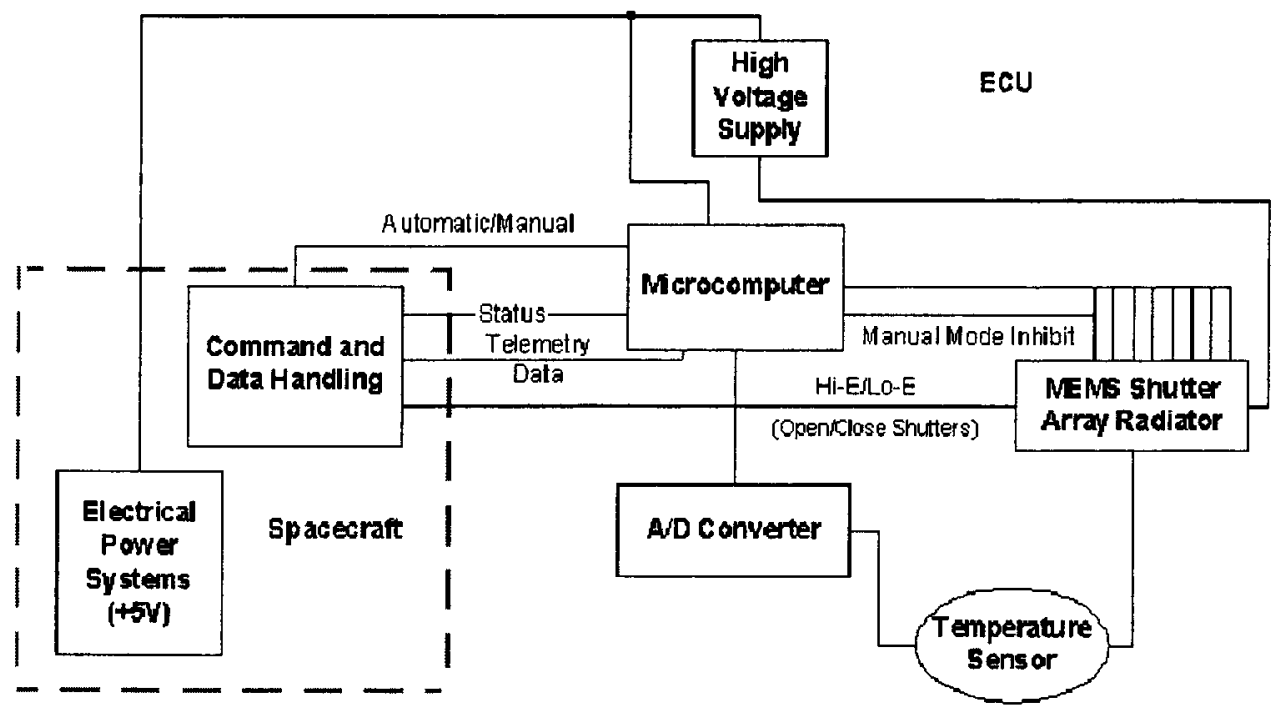

FIGURE 1. Performance Illustration.

This diagram depicts the various processes carried out by the ECU, thereby revealing its significance for such an experiment. The overall performance process is a follows: The Electrical Power System (EPS) supplies $5.23 \pm 0.1$ volts to the ECU. The 5.23 volts powers the microcomputer and is then stepped up to 30 volts to properly power the MEMS comb drives. Once powered, the MEMS instrument can now be properly controlled. At such time, the microcomputer sends its status information out to $\mathrm{C} \& \mathrm{DH}$, and awaits command. C\&DH sends two different bi-level commands to the ECU, which are examined and executed via the ECU. The bi-level commands are Automatic/Manual and Hi-E/Lo-E. These two bi-level commands tell the ECU whether its processing unit will be in full control of the MEMS device, or if C\&DH will command the state of the shutters. Provided C\&DH sends the Automatic command to the ECU, the ECU is in total control of the MEMS device. In Automatic mode, the microcomputer is capable of controlling each section of the MEMS device independently. The MSA radiator design consists of 36 MEMS Shutter Dies (MSD), with 18 MSD per section. The MSD is $12.8 \mathrm{~mm} \mathrm{x}$ $13.1 \mathrm{~mm}$, consisting of 72 MEMS Shutter Building Block (MSBB). The MSBB is the smallest shutter unit, 1.77 $\mathrm{mm} \times .88 \mathrm{~mm}$, driven simultaneously by $6 \mathrm{comb}$ drive units. The radiator layout for the technology, as well as an enlarged image of the MEMS Shutter Building Block (MSBB) is provided in Figures 2 and 3. 


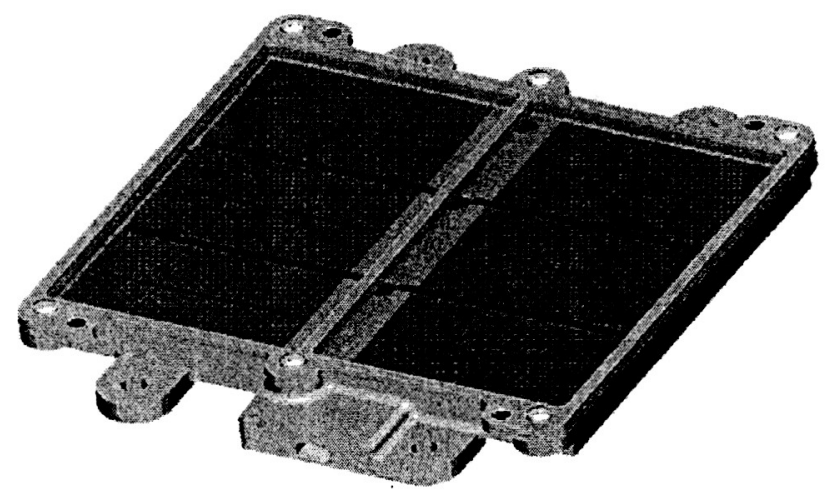

FIGURE 2. MSA Radiator.

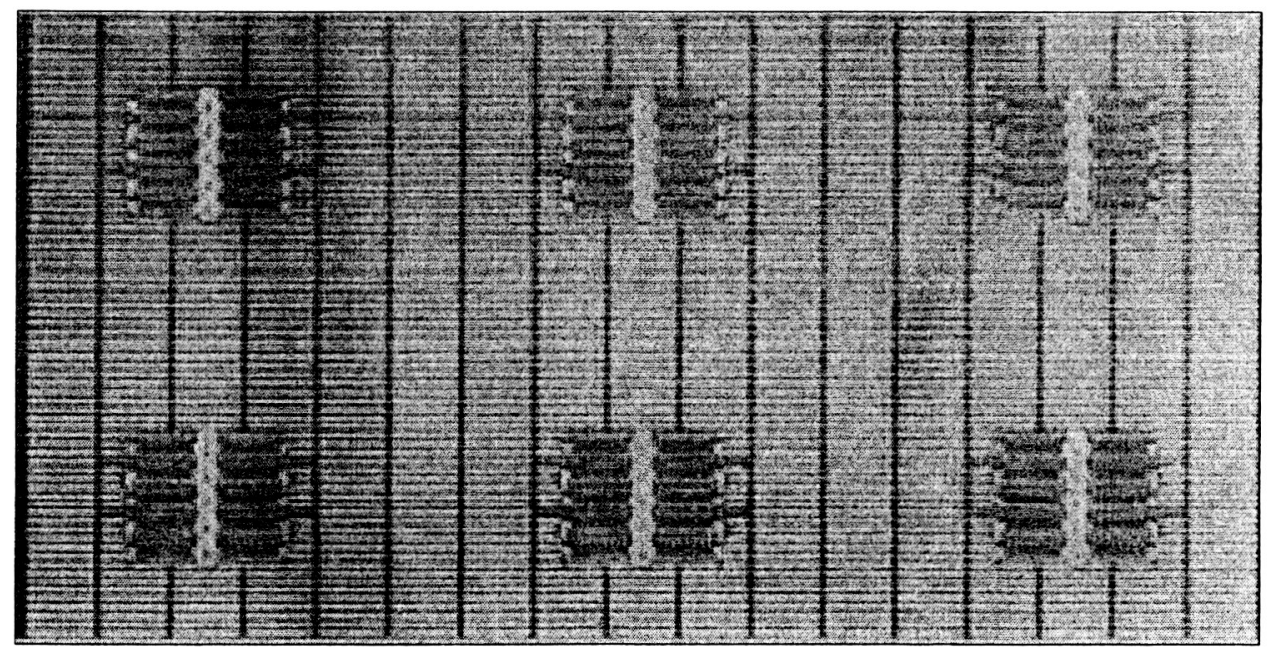

FIGURE 3. MEMS Shutter Building Block ( $w / 6$ comb drive units).

\section{ELECTRICAL INTERFACE}

The instrument is powered by a $5.23 \mathrm{~V} \pm 0.1 \mathrm{~V}$ supply from the Electrical Power System (EPS). The estimated current consumption thus far is as follows:

- High Voltage Generator -- $1 \mathrm{~mA}$

- Microcomputer -- $8 \mathrm{~mA} @ 1.3824 \mathrm{MHz}$

- Program Memory (8K x 8 PROM)@1.3824 MHz -- 5 mA

- Analog Circuitry -- $6.4 \mathrm{~mA}$

Estimated Average Current $=20.4 \mathrm{~mA}$

Maximum Current Allocated (w/o Heater) $=43.4 \mathrm{~mA}$ average and $73 \mathrm{~mA}$ peak

Maximum Current Allocated (w/ Heater) $=343.4 \mathrm{~mA}$ average and $373 \mathrm{~mA}$ peak 


\section{MICROCOMPUTER FUNCTIONS}

Following are brief descriptions of the microcomputer functions performed during this experiment:

- Boot-up and health check

- Self check - ROM and RAM

- Check high voltage generator, temperature reading, and load fault line

- Run health check on each shutter subsection

- Ready watchdog timer

- Periodically read temperature, determine $\Delta t$, and make correction by opening and closing appropriate shutter sections

- As shutter sections are powered, monitor the steady state current draw for operational health

- Update the shutter command states and shutter health states as needed

- Update telemetry

\section{COMMAND AND DATA INTERFACE}

C\&DH interfaces with the ECU via two bi-level command lines, two twisted pair thermistor lines, a status line, and a twisted pair signal line that contains time-multiplexed analog telemetry data. The status line is active in both Automatic and Manual mode to indicate that the ECU has performed it's self-test and is ready to send valid telemetry (TM) data. After power is turned on, it takes $\sim 1$ to 2 seconds for the high voltage power supply to stabilize. After such time, several seconds $(\sim 5-10)$ will be required for a diagnostic test to be conducted. Prior to such test, telemetry data will be undefined. Upon completion of the diagnostic test, the status line will go high, and the TM data will be valid.

\section{Digital Commands}

The two bi-level commands, Automatic/Manual and Hi-E/Lo-E, along with the switched power from the C\&DH, will form four modes of operation as shown in Table 1. In each of the modes, the high voltage supply and microcontroller will always be active. The default mode $\left(^{*}\right)$ of operation is the Manual mode, low emittance (Lo-E) state.

TABLE 1. Operational Modes.

\begin{tabular}{|c|c|c|c|c|}
\hline Mode & Pover On (5v) & Antomaticmand & WHITr- & WMGMSTCUster \\
\hline 0 & 1 & 0 & 0 & $\begin{array}{c}\text { Manual mode/all shutters } \\
\text { closed (*) }\end{array}$ \\
\hline 1 & 1 & 0 & 1 & $\begin{array}{c}\text { Manual mode/all shutters } \\
\text { open }\end{array}$ \\
\hline 2 & 1 & 1 & $X$ & $\begin{array}{l}\text { Automatic mode/no heater } \\
\text { power available }\end{array}$ \\
\hline 3 & 1 & 1 & $X$ & $\begin{array}{l}\text { Automatic mode/heater } \\
\text { power available }\end{array}$ \\
\hline
\end{tabular}

\section{Instrument Operation}

The functions performed by the instrument in each mode of operation are:

If mode zero is selected, the shutters will be positioned according to the default mode of operation, Manual mode, Lo-E (All shutters closed). The high voltage power supply will provide $1 \mathrm{~Hz}$ pulses, of $30 \mathrm{~V}$ each, every second for $10 \mathrm{~ms}$ to the shutters to actuate them and ensure their operability. The substrate temperature will be monitored with 6 thermistors. 
If mode one is selected, all shutters will be positioned in the Hi-E state (All shutters open). The high voltage will be interrupted with $1 \mathrm{~Hz}$ pulses, $0 \mathrm{~V}, 10 \mathrm{~ms}$ long to actuate the shutters and ensure their operability. The substrate temperature will be monitored with 6 thermistors.

If mode two is selected, the ECU will be operated in automatic mode. The substrate temperature will be monitored with 6 thermistors. Once in the automatic mode, the microprocessor will issue commands to the MSA radiator to open/close shutter sections following the experimental microprocessor functions/procedures provided herein. The substrate temperature of the MSA radiator is monitored and transmitted to the C\&DH according to the required telemetry scheme. No heater power will exist to operate the heater in this mode.

If mode three is selected, the ECU will be operated in automatic mode, following the same sequence as mode two; however, heater power will be available during this mode. The substrate temperature will be monitored with 6 thermistors and transmitted to $\mathrm{C} \& \mathrm{DH}$ according to the required telemetry scheme. The availability of heater power permits use of the heater, under our control.

\section{PACKAGE REQUIREMENTS}

The total weight of the instrument shall not exceed $350 \mathrm{~g}$. This includes all electronics, housing material, connectors, etc. The MSA radiator is constrained to a $10 \mathrm{~cm}(\mathrm{~L}) \times 9 \mathrm{~cm}(\mathrm{~W}) \times 3 \mathrm{~cm}(\mathrm{H})$ envelope. The ECU will be housed in a $8.77 \times 8.77 \times 3.9 \mathrm{~cm}$ package. Micro-D-Metal (MDM) connectors will be used for the interfaces between C\&DH and the ECU, and the ECU to the MSA radiator. The spacecraft bus will provide most of the radiation shielding for this experiment; however, if additional shielding is required, other shielding measures/methods will be used.

\section{ENVIRONMENTAL TEST REQUIREMENTS}

Several environmental tests must be conducted before the final flight design. Table 2 provides a summarized list of the various performance tests that will be conducted to verify part survival. In addition to the test listed, life cycling tests, performance measurements (both effective IR emissivity and solar absorptivity), cycling in vacuum (over 1000 times), and exposure to a simulated space environment in GSFC's Solar Wind and UV facilities will be conducted.

TABLE 2. Environmental Test.

\begin{tabular}{|l|l|}
\hline Test & Conditions \\
\hline Random Vibration & $\begin{array}{l}\text { Flight (Limit) Level }+3 \mathrm{~dB}, \text { Flight } \\
\text { Duration/axis; } 3 \text { axes }\end{array}$ \\
\hline Sinusoidal Vibration & $\begin{array}{l}1.25 \times \text { Flight (Limit) Level, Flight } \\
\text { Duration/axis; } 3 \text { axes } 4 \text { oct/min }\end{array}$ \\
\hline Acoustics & Flight (Limit) Level + 3dB, Flight Duration \\
\hline Structural Loads & Test: $1.25 \times$ Flight (Limit) Loads, Analysis: \\
& $1.4 \times$ Flight (Limit) Loads \\
\hline Mechanical Shock & Analysis: $1.4 \times$ Flight (Limit) Level \\
\hline Thermal Cycle/Vacuum & -60 to $+60^{\circ} \mathrm{C}, 4$ cycles (min), $1 \times 10^{-5}$ Torr \\
\hline Bum In & $100 \%\left(125^{\circ} \mathrm{C}, 160\right.$ hours min) \\
\hline
\end{tabular}

\section{DISCUSSION OF THERMAL ANALYSES}

A qualitative analysis was conducted to validate the performance of the MEMS device as a radiator. Figure 3 provides results from the analysis as a function of conductance. This analysis was conducted with and without a heater, to evaluate whether a large enough $\Delta \mathrm{T}$ would be observed between the spacecraft and the technology, in the 
low and high emittance states. Based on the assumptions below, and a dynamic emittance of 0.3 , the qualitative results from the study conducted are as follows:
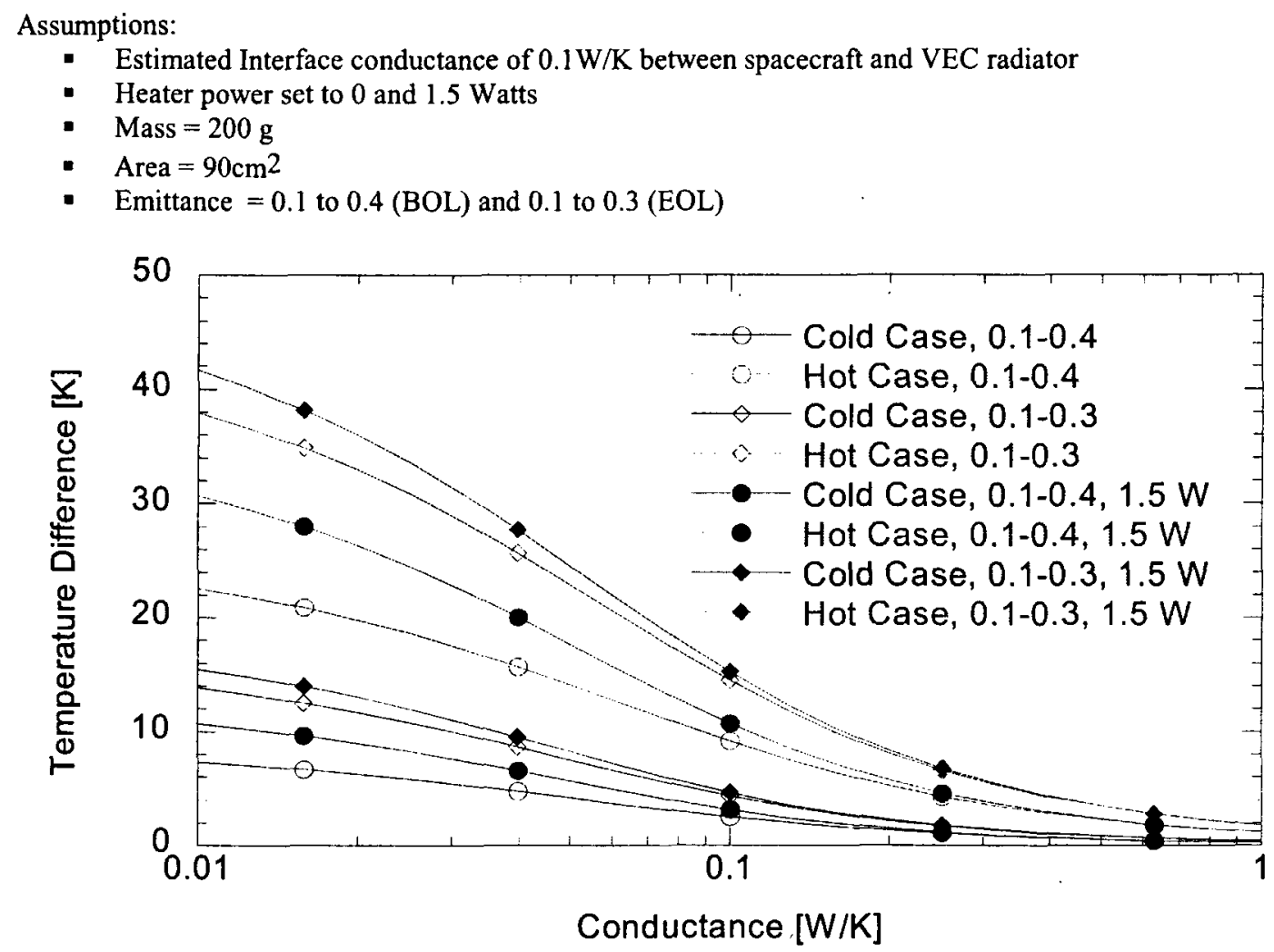

FIGURE 3. Temperature difference between high and low emissivity case for different emissivities as a function of the (parasitic) conduction.

The above studies reveal that for effective validation of the technology as a radiator, a 1.5 watt heater is beneficial, at all of the tested emittance levels. Furthermore, a heater would be beneficial if utilized as a means for calibrating the MSA device. In addition, the $0.1 \mathrm{~W} / \mathrm{K}$ interface conductance is sufficient in keeping the radiator temperatures above their survival limits and yielding temperature gradients adequate for validation. From this analysis, with the goal being to verify whether a large enough $\Delta \mathrm{T}$ would exist to effectively evaluate the MEMS device as a variable emittance coating (VEC), it was concluded that a heater will be used in the experiment to provide enough of a temperature gradient to thoroughly evaluate the MSA radiator performance.

\section{CONCLUSION}

It has been shown in multiple models ${ }^{[4]}$ that VEC technology offers significant advantages over current approaches for radiators in low UV environments. The heater power, mass, and cost savings that can be realized with these systems are potentially significant for many future spacecraft design applications. In addition, VEC coatings allow a more flexible thermal design, which is important for spacecraft such as ST5 that are launched as a secondary payload and the orbit parameters are not well defined during the design period. The ST5 mission will demonstrate three VEC technologies and, if successful, provide validation for their use on future spacecraft. There are a number of challenges connected with this project. The technology as a whole will undergo a very strict space qualification test schedule, for which so far only CMOS devices can be used as a reference. 
The shutter status will be recorded during flight for the first time, with the mission scheduled to last for 6 months. Also, information on the performance of actuated MEMS structures in the space environment will be gathered and provide guidelines for future designs.

At this point, fully actuated prototypes of the MEMS shutter arrays have been fabricated and are undergoing critical reliability and space qualification testing. The electronics responsible for operating the MEMS device have been selected to ensure that the radiation levels and extended temperature ranges will be met.

\section{ACKNOWLEDGMENTS}

APL is the principal investigator of the Variable Emittance (MEMS) Electronic Control Unit, and the MSA Radiator. The MEMS wafers are fabricated at Sandia National Laboratories. Funding is provided by the NASA GSFC Thermal Control Branch and ST-5 Project Team.

\section{NOMENCLATURE}

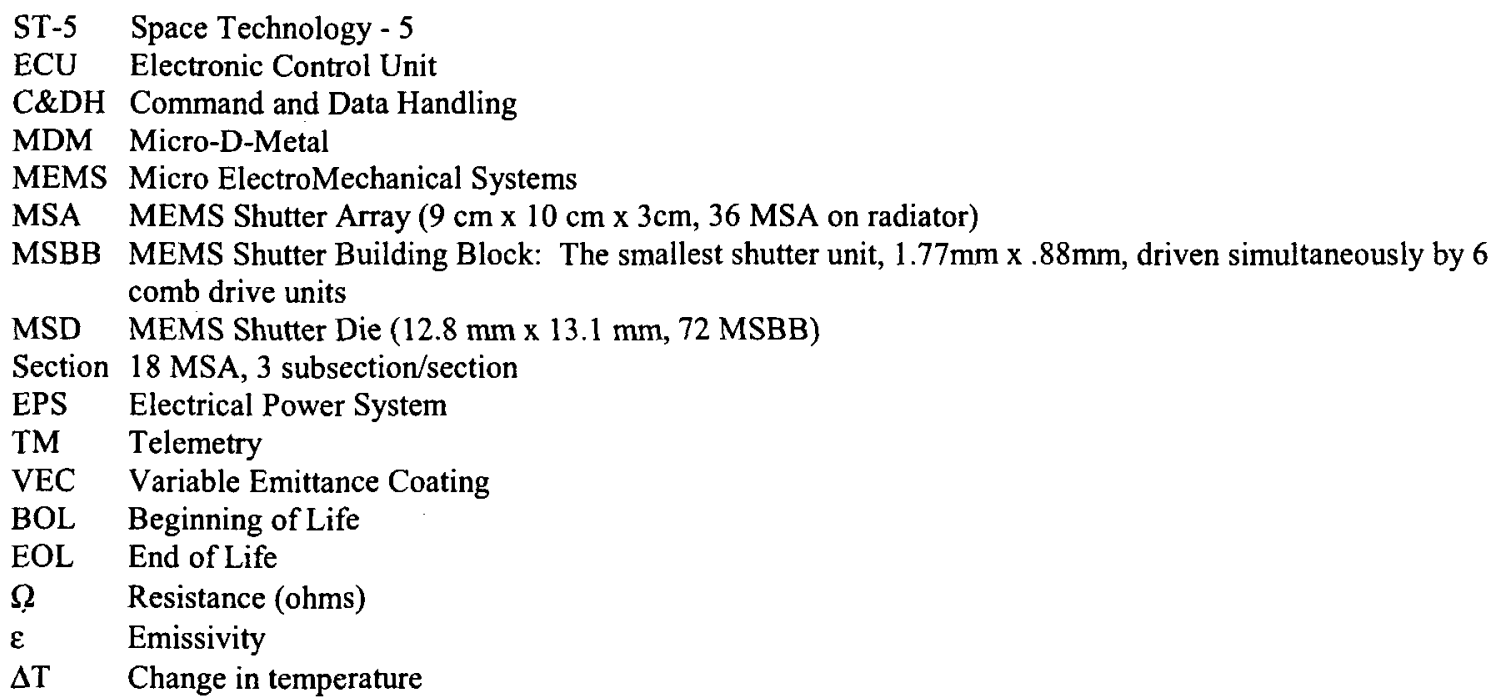

\section{REFERENCES}

Garrison Darrin, A, Osiander, R., Champion, J.L., Swanson, T.D., Douglas, D. Grob, L.M., "Variable Emissivity Through MEMS Technology," in proceedings of Space Technology and Applications International Forum (STAIF-2000), edited by M. El-Genk, AIP Conference Proceedings, New York, 2000, pp. 947-961.

Douglas, D.M., Swanson, T.D., Osiander, R., Champion, J.L., Garrison Darrin, A., Biter, W, Chandrasekhar, P., "Development of the Variable Emittance Thermal Suite for the Space Technology 5 Microsatellite," to be presented at the Space Technology and Applications International Forum (STAIF), Albuquerque, NM, February 2002 .

Grob, L.M., Swanson, T.D., "Parametric Study of Variable Emissivity Radiator Surfaces," in proceedings of Space Technology and Applications International Forum (STAIF-2000), edited by M. El-Genk, AIP Conference Proceedings, New York, 2000, pp. 809-814.

Osiander, R., Champion J.L., Darrin, A.M., Sniegowski, J.J., Rodgers, S.M., Douglas, D., Swanson, T.D., "Micromachined Louver Arrays for Spacecraft Thermal Control Radiators," American Institute of Aeronautics and Astronautics, Inc. AIAA-2001-0215, 2001. 